\title{
Some common fixed points of multivalued mappings on complex-valued metric spaces with homotopy result
}

\author{
Wasfi Shatanawi ${ }^{\mathrm{a}, \mathrm{b}, *}$, Mohd Salmi MD Noorani $^{\mathrm{c}}$, Jamshaid Ahmad ${ }^{\mathrm{d}}$, Habes Alsamir ${ }^{\mathrm{c}}$, Marwan Amin Kutbi \\ ${ }^{a}$ Department of Mathematics and general courses, Prince Sultan University Riyadh, Saudi Arabia. \\ ${ }^{b}$ Department of Mathematics, Hashemite University Zarqa, Jordan. \\ ${ }^{c}$ School of mathematical Sciences, Faculty of Science and Technology, University Kebangsaan, Malaysia, 43600 UKM, Selangor, \\ Malaysia. \\ ${ }^{d}$ Department of Mathematics, University of Jeddah, P. O. Box 80327, Jeddah 21589, Saudi Arabia. \\ ${ }^{e}$ Department of Mathematics, King Abdulaziz University, P. O. Box 80203, Jeddah 21589, Saudi Arabia.
}

Communicated by M. De la Sen

\begin{abstract}
The purpose of this article is to generalize common fixed point theorems under contractive condition involving rational expressions on a complete complex-valued metric space. Obtained results in this article extend, generalize, and improve wellknown comparable results in the literature. (C)2017 All rights reserved.
\end{abstract}

Keywords: Complex-valued metric space, multivalued mappings, $\alpha^{*}$-admissible, closed ball. 2010 MSC: 47H10, 54H25.

\section{Introduction and preliminaries}

The Banach's fixed point theorem [8] was also used to establish the existence of a unique solution for a nonlinear integral equation. Moreover, this theorem plays an important role in several branches of mathematics. For instance, it has been used to show the existence of solutions of nonlinear Volterra integral equations, nonlinear integro-differential equations in Banach spaces and to show the convergence of algorithms in computational mathematics. Because of its importance and usefulness for mathematical theory, it has been become a very popular tool in solving existence problems in many directions. Several authors have obtained various extensions and generalizations of Banach's theorem by defining a variety of contractive type conditions for self and non-self-mappings on metric spaces.

Nadler [19] extended Banach's contraction principle to multivalued contraction mappings. Many extensions of Nadler's result have been derived in recent years. In 2011 Cho et al. [9] initiated the concept of Housdorff distance function for the cone metric spaces and established some fixed point results.

\footnotetext{
*Corresponding author

Email addresses: wshatanawi@psu.edu.sa, swasfi@hu.edu.jo (Wasfi Shatanawi), msn@ukm.my (Mohd Salmi MD Noorani), jamshaid_jasim@yahoo.com (Jamshaid Ahmad), h.alsamer@gmail.com (Habes Alsamir), mkutbi@yahoo.com (Marwan Amin Kutbi)

doi:10.22436/jnsa.010.07.02
} 
Azam et al. [7] introduced the concept of complex-valued metric spaces and proved some common fixed point results for a pair of single-valued mappings. They explained that complex-valued metric spaces form a special class of cone metric spaces. The results involving rational expressions which are meaningless in cone metric spaces are discussed in complex-valued metric spaces. Subsequently, Abbas et al. [1, 2], Klin-eam et al. [15], Rouzkard et al. [20], Sintunavarat et al. [22, 23], and Sitthikul et al. [24], established common fixed point theorems satisfying certain rational expressions in complex-valued metric spaces which generalize, unify and complement the results of Azam et al. [7]. For more details we refer to the reader $[3,4,6,16,17]$.

Recently Samet et al. [21] introduced the concepts $\alpha$-admissible mappings and obtained fixed point results for such mappings in complete metric spaces. In [11], Asl generalized the concept of $\alpha$-admissible by introducing coupled $\alpha$-admissible and obtained some common fixed point results for self-mappings. Very recently, Kutbi et al. [16] introduced $\alpha^{*}-\psi$-contractive multivalued mappings and obtained some fixed point results for such mappings in cone metric space. For more details in $\alpha$-admissible mappings and $\alpha^{*}$-admissible multivalued mappings, we refer the reader to $[5,10,12-14,17,18]$.

In this article, we define the notion of coupled $\alpha^{*}$-admissible mappings for complex-valued metric spaces and obtain common fixed points of mutivalued mappings in connection with Hausdorff distance function for closed bounded subsets of complex-valued metric spaces. Let $\mathbb{C}$ be the set of complex numbers and $z_{1}, z_{2} \in \mathbb{C}$. Define a partial order $\precsim$ on $\mathbb{C}$ as follows:

$$
z_{1} \precsim z_{2} \text { if and only if } \operatorname{Re}\left(z_{1}\right) \leqslant \operatorname{Re}\left(z_{2}\right), \operatorname{Im}\left(z_{1}\right) \leqslant \operatorname{Im}\left(z_{2}\right) \text {. }
$$

It follows that $z_{1} \precsim z_{2}$ if one of the following conditions is satisfied:

(i) $\operatorname{Re}\left(z_{1}\right)=\operatorname{Re}\left(z_{2}\right), \operatorname{Im}\left(z_{1}\right)<\operatorname{Im}\left(z_{2}\right)$,

(ii) $\operatorname{Re}\left(z_{1}\right)<\operatorname{Re}\left(z_{2}\right), \operatorname{Im}\left(z_{1}\right)=\operatorname{Im}\left(z_{2}\right)$,

(iii) $\operatorname{Re}\left(z_{1}\right)<\operatorname{Re}\left(z_{2}\right), \operatorname{Im}\left(z_{1}\right)<\operatorname{Im}\left(z_{2}\right)$,

(iv) $\operatorname{Re}\left(z_{1}\right)=\operatorname{Re}\left(z_{2}\right), \operatorname{Im}\left(z_{1}\right)=\operatorname{Im}\left(z_{2}\right)$.

In particular, we will write $z_{1} \precsim z_{2}$ if $z_{1} \neq z_{2}$ and one of (i), (ii), and (iii) is satisfied and we will write $z_{1} \prec z_{2}$ if only (iii) is satisfied. Note that

$$
0 \precsim z_{1} \precsim z_{2} \Longrightarrow\left|z_{1}\right|<\left|z_{2}\right|, \quad z_{1} \preceq z_{2}, z_{2} \prec z_{3} \Longrightarrow z_{1} \prec z_{3} .
$$

Definition 1.1. Let $X$ be a non-empty set. Suppose that a mapping $d: X \times X \rightarrow \mathbb{C}$ satisfies:

1. $0 \precsim d(x, y)$, for all $x, y \in X$ and $d(x, y)=0$ if and only if $x=y$;

2. $d(x, y)=d(y, x)$ for all $x, y \in X$;

3. $\mathrm{d}(x, y) \precsim \mathrm{d}(x, z)+\mathrm{d}(z, y)$ for all $x, y, z \in X$.

Then $d$ is called a complex-valued metric on $X$, and $(X, d)$ is called a complex-valued metric space. Given a subset $P$ of $\mathbb{C}$, we define a partial ordering $\succ$ with respect to $P$ and $P=\{z \in \mathbb{C}: z \succ 0\}$. A point $x \in X$ is called interior point of a set $A \subseteq X$ whenever there exists $0 \prec r \in \mathbb{C}$ such that

$$
B(x, r)=\{y \in X: d(x, y) \prec r\} \subseteq A,
$$

where $B(x, r)$ is an open ball. Then $\bar{B}(x, r)=\{y \in X: d(x, y) \preceq r\}$ is a closed ball in the context of complexvalued metric space.

A point $x \in X$ is called a limit point of $A$ whenever for every $0 \prec r \in \mathbb{C}$,

$$
\mathrm{B}(x, \mathrm{r}) \cap(\mathrm{A} \backslash\{x\}) \neq \phi .
$$

$A$ is called open whenever each element of $A$ is an interior point of $A$. Moreover, a subset $B \subseteq X$ is called closed whenever each limit point of B belongs to B. The family

$$
F=\{B(x, r): x \in X, 0 \prec r\}
$$


is a sub-basis for a Hausdorff topology $\tau$ on $X$.

Let $x_{n}$ be a sequence in $X$ and $x \in X$. If for every $c \in \mathbb{C}$ with $0 \prec c$ there is $n_{0} \in \mathbb{N}$ such that for all $n>n_{0}, d\left(x_{n}, x\right) \prec c$, then $\left\{x_{n}\right\}$ is said to be convergent, $\left\{x_{n}\right\}$ converges to $x$ and $x$ is the limit point of $\left\{x_{n}\right\}$. We denote this by $\lim _{n \rightarrow \infty} x_{n}=x$, or $x_{n} \longrightarrow x$, as $n \rightarrow \infty$. If for every $c \in \mathbb{C}$ with $0 \prec c$ there is $n_{0} \in \mathbb{N}$ such that for all $n>n_{0}, d\left(x_{n}, x_{n+m}\right) \prec c$, then $\left\{x_{n}\right\}$ is called a Cauchy sequence in $(X, d)$. If every Cauchy sequence is convergent in $(X, d)$, then $(X, d)$ is called a complete complex-valued metric space. We require the following lemmas.

Lemma $1.2([7])$. Let $(X, d)$ be a complex-valued metric space and let $\left\{x_{n}\right\}$ be a sequence in $X$. Then $\left\{x_{n}\right\}$ converges to $x$ if and only if $\left|\mathrm{d}\left(\mathrm{x}_{\mathrm{n}}, \mathrm{x}\right)\right| \rightarrow 0$ as $\mathrm{n} \rightarrow \infty$.

Lemma 1.3 ([7]). Let $(\mathrm{X}, \mathrm{d})$ be a complex-valued metric space and let $\left\{x_{\mathrm{n}}\right\}$ be a sequence in $\mathrm{X}$. Then $\left\{\mathrm{x}_{\mathrm{n}}\right\}$ is a Cauchy sequence if and only if $\left|\mathrm{d}\left(\mathrm{x}_{\mathrm{n}}, \mathrm{x}_{\mathrm{n}+\mathrm{m}}\right)\right| \rightarrow 0$ as $\mathrm{n} \rightarrow \infty$.

\section{Main results}

Let $(X, d)$ be a complex-valued metric space. We denote nonempty, closed, and bounded subset of $X$ by $\mathrm{CB}(\mathrm{X})$. From now on, we denote $\mathrm{s}\left(z_{1}\right)=\left\{z_{2} \in \mathbb{C}: z_{1} \preceq z_{2}\right\}$ for $z_{1} \in \mathbb{C}$, and $s(a, B)=\cup_{b \in B}$ $s(d(a, b))=\underset{b \in B}{\cup}\{z \in \mathbb{C}: d(a, b) \preceq z\}$ for $a \in X$ and $B \in C B(X)$. For $A, B \in C B(X)$ we denote

$$
s(A, B)=(\underset{a \in A}{\cap} s(a, B)) \cap(\underset{b \in B}{\cap} s(b, A)) .
$$

Lemma 2.1. Let $(\mathrm{X}, \mathrm{d})$ be a complex-valued metric space.

(1) Let $\mathrm{p}, \mathrm{q} \in \mathbb{C}$. If $\mathrm{p} \preceq \mathrm{q}$, then $\mathrm{s}(\mathrm{q}) \subset \mathrm{s}(\mathrm{p})$.

(2) Let $x \in X$ and $A \in N(X)$. If $\theta \in s(x, A)$, then $x \in A$.

(3) Let $\mathrm{q} \in \mathrm{P}$ and let $\mathrm{A}, \mathrm{B} \in \mathrm{CB}(\mathrm{X})$ and $\mathrm{a} \in \mathrm{A}$. If $\mathrm{q} \in \mathrm{s}(\mathrm{A}, \mathrm{B})$, then $\mathrm{q} \in \mathrm{s}(\mathrm{a}, \mathrm{B})$ for all $\mathrm{a} \in \mathrm{A}$ or $\mathrm{q} \in \mathrm{s}(\mathrm{A}, \mathrm{b})$ for all $\mathrm{b} \in \mathrm{B}$.

(4) Let $\mathrm{q} \in \mathrm{P}$ and let $\lambda \geqslant 0$, then $\lambda \mathrm{s}(\mathrm{q}) \subseteq \mathrm{s}(\lambda \mathrm{q})$.

Remark 2.2. Let $(X, d)$ be a complex-valued metric space. If $C=R$, then $(X, d)$ is a metric space. Moreover for $A, B \in C B(X), H(A, B)=\inf s(A, B)$ is the Hausdorff distance induced by $d$.

Definition 2.3. Let $(X, d)$ be a complex-valued metric space and $C B(X)$ be a collection of nonempty closed and bounded subsets of $X$. Let $T: X \rightarrow C B(X)$ be a multivalued map. For $x \in X$, and $A \in C B(X)$, define

$$
W_{x}(A)=\{d(x, a): a \in A\} .
$$

Thus for $x, y \in X$

$$
W_{x}(T y)=\{d(x, u): u \in T y\}
$$

Definition 2.4. Let $(X, d)$ be a complex-valued metric space. A non-empty subset $A$ of $X$ is called bounded from below if there exists some $z \in \mathbb{C}$, such that $z \preceq a$ for all $a \in A$.

Definition 2.5. Let $(X, d)$ be a complex-valued metric space. A multivalued mapping $F: X \rightarrow 2^{\mathbb{C}}$ is called bounded from below if for $x \in X$ there exists $z_{x} \in \mathbb{C}$ such that $z_{x} \preceq u$ for all $u \in F x$.

Definition 2.6. Let $(X, d)$ be a complex-valued metric space. The multivalued mapping $T: X \rightarrow C B(X)$ said to have lower bound property (l.b property) on $(X, d)$, if for any $x \in X$, the multivalued mapping $\mathrm{F}_{\mathrm{x}}: \mathrm{X} \rightarrow 2^{\mathrm{C}}$ defined by,

$$
F_{x}(T y)=W_{x}(T y)
$$

is bounded from below. That is, for $x, y \in X$ there exists an element $l_{x}(T y) \in \mathbb{C}$ such that

$$
l_{x}(T y) \preceq u
$$

for all $u \in W_{x}(T y)$, where $l_{x}(T y)$ is called lower bound of $T$ associated with $(x, y)$. 
Definition 2.7. Let $(X, d)$ be a complex-valued metric space. The multivalued mapping $T: X \rightarrow C B(X)$ said to have the greatest lower bound property (g.l.b property) on $(X, d)$, if the greatest lower bound of $W_{x}(T y)$ exists in $\mathbb{C}$ for all $x, y \in X$. We denote $d(x, T y)$ by the g.l.b of $W_{x}(T y)$. That is,

$$
d(x, T y)=\inf \{d(x, u): u \in T y\} .
$$

Definition 2.8. Let $S, T: X \rightarrow C B(X)$, and let $\alpha: X \times X \rightarrow[0,+\infty)$. One says that $S, T$ are coupled $\alpha^{*}$-admissible if $\alpha(x, y) \geqslant 1$ implies $\alpha^{*}(S x, T y) \geqslant 1$ for all $x, y \in X$, where

$$
\alpha^{*}(S x, T y)=\inf \{\alpha(x, y): x \in S x, y \in T y\} .
$$

Theorem 2.9. Let $\mathrm{S}, \mathrm{T}: \mathrm{X} \longrightarrow \mathrm{CB}(\mathrm{X})$ be coupled $\alpha^{*}$-admissible mappings with g.l.b property on complete complexvalued metric space $(\mathrm{X}, \mathrm{d}), \mathrm{x}_{0} \in \mathrm{X}$ and $0 \prec \mathrm{r} \in \mathbb{C}$. If $\mathrm{S}$ and $\mathrm{T}$ satisfy

$$
\lambda d(x, y)+\frac{\mu d(x, S x) d(y, T y)+\gamma d(y, S x) d(x, T y)}{1+d(x, y)} \in \alpha^{*}(S x, T y) s(S x, T y)
$$

for all $x, y \in \overline{\mathrm{B}}\left(\mathrm{x}_{0}, \mathrm{r}\right)$, then

$$
(1-k) r \in s\left(x_{0}, S x_{0}\right),
$$

where $\lambda, \mu$ and $\gamma$ are non-negative real numbers with $\mathrm{k}=\frac{\lambda}{1-\mu}<1$. Suppose that there exist $x_{0} \in X, x_{1} \in \bar{B}\left(x_{0}, r\right)$ such that $\alpha\left(x_{0}, x_{1}\right) \geqslant 1$. Assume that if $\left\{x_{n}\right\}$ is a sequence in $\bar{B}\left(x_{0}, r\right)$ such that $\alpha\left(x_{n}, x_{n+1}\right) \geqslant 1$ and $x_{n} \rightarrow u$ as $\mathrm{n} \rightarrow+\infty$, then $\alpha\left(\mathrm{x}_{\mathrm{n}}, \mathrm{u}\right) \geqslant 1$ for all $\mathrm{n}$. Then, there exists a point $\mathrm{x}^{*}$ in $\overline{\mathrm{B}}\left(\mathrm{x}_{0}, \mathrm{r}\right)$ such that $\mathrm{x}^{*} \in \mathrm{S} \mathrm{x}^{*} \cap \mathrm{T} \mathrm{x}^{*}$.

Proof. Let $x_{0}$ be an arbitrary point in $X$. From (2.2), we have

$$
(1-k) r \in s\left(x_{0}, S x_{0}\right), \quad(1-k) r \in \underset{x \in S x_{0}}{\bigcup} s\left(d\left(x_{0}, x_{1}\right)\right) .
$$

As $S x_{0} \in C B(X)$, so is non-empty then there exists some $x_{1} \in S x_{0}$ such that

$$
(1-k) r \in s\left(d\left(x_{0}, x_{1}\right)\right) .
$$

From the definition, we get

$$
\mathrm{d}\left(\mathrm{x}_{0}, \mathrm{x}_{1}\right) \preceq(1-\mathrm{k}) \mathrm{r}
$$

which implies that

$$
\left|\mathrm{d}\left(\mathrm{x}_{0}, \mathrm{x}_{1}\right)\right| \leqslant(1-\mathrm{k})|\mathrm{r}| \text {. }
$$

Thus $x_{1} \in \bar{B}\left(x_{0}, r\right)$. Since $\alpha\left(x_{0}, x_{1}\right) \geqslant 1$ and the pair $\{S, T\}$ is coupled $\alpha^{*}$-admissible, so $a^{*}\left(S x_{0}, T x_{1}\right) \geqslant 1$. From (2.1), we get

$$
\lambda d\left(x_{0}, x_{1}\right)+\frac{\mu d\left(x_{0}, S x_{0}\right) d\left(x_{1}, T x_{1}\right)+\gamma d\left(x_{1}, S x_{0}\right) d\left(x_{0}, T x_{1}\right)}{1+d\left(x_{0}, x_{1}\right)} \in a^{*}\left(S x_{0}, T x_{1}\right) s\left(S x_{0}, T x_{1}\right) .
$$

By lemma 4(3), we have

$$
\lambda d\left(x_{0}, x_{1}\right)+\frac{\mu d\left(x_{0}, S x_{0}\right) d\left(x_{1}, T x_{1}\right)+\gamma d\left(x_{1}, S x_{0}\right) d\left(x_{0}, T x_{1}\right)}{1+d\left(x_{0}, x_{1}\right)} \in a^{*}\left(S x_{0}, T x_{1}\right) s\left(x_{1}, T x_{1}\right) .
$$

By the definition there exists some $x_{2} \in T x_{1}$, such that

$$
\lambda d\left(x_{0}, x_{1}\right)+\frac{\mu d\left(x_{0}, S x_{0}\right) d\left(x_{1}, T x_{1}\right)+\gamma d\left(x_{1}, S x_{0}\right) d\left(x_{0}, T x_{1}\right)}{1+d\left(x_{0}, x_{1}\right)} \in a^{*}\left(S x_{0}, T x_{1}\right) s\left(d\left(x_{1}, x_{2}\right)\right) .
$$

By the definition and Lemma 2.1 (4), we get

$$
a^{*}\left(S x_{0}, T x_{1}\right) d\left(x_{1}, x_{2}\right) \preceq \lambda d\left(x_{0}, x_{1}\right)+\frac{\mu d\left(x_{0}, S x_{0}\right) d\left(x_{1}, T x_{1}\right)+\gamma d\left(x_{1}, S x_{0}\right) d\left(x_{0}, T x_{1}\right)}{1+d\left(x_{0}, x_{1}\right)} .
$$


By using the greatest lower bound property (g.l.b property) of $S$ and $T$, we get

$$
a^{*}\left(S x_{0}, T x_{1}\right) d\left(x_{1}, x_{2}\right) \preceq \lambda d\left(x_{0}, x_{1}\right)+\frac{\mu d\left(x_{0}, x_{1}\right) d\left(x_{1}, x_{2}\right)+\gamma d\left(x_{1}, x_{1}\right) d\left(x_{0}, x_{2}\right)}{1+d\left(x_{0}, x_{1}\right)} .
$$

Hence

$$
0 \prec d\left(x_{1}, x_{2}\right) \preceq a^{*}\left(S x_{0}, T x_{1}\right) d\left(x_{1}, x_{2}\right) \preceq \lambda d\left(x_{0}, x_{1}\right)+\frac{\mu d\left(x_{0}, x_{1}\right) d\left(x_{1}, x_{2}\right)}{1+d\left(x_{0}, x_{1}\right)},
$$

which implies that

$$
\begin{aligned}
& \left|d\left(x_{1}, x_{2}\right)\right| \leqslant \lambda\left|d\left(x_{0}, x_{1}\right)\right|+\frac{\mu\left|d\left(x_{0}, x_{1}\right)\right|\left|d\left(x_{1}, x_{2}\right)\right|}{\left|1+d\left(x_{0}, x_{1}\right)\right|}=\lambda\left|d\left(x_{0}, x_{1}\right)\right|+\mu\left|d\left(x_{1}, x_{2}\right)\right|\left|\frac{d\left(x_{0}, x_{1}\right)}{1+d\left(x_{0}, x_{1}\right)}\right| \\
& \left|d\left(x_{1}, x_{2}\right)\right| \leqslant \lambda\left|d\left(x_{0}, x_{1}\right)\right|+\mu\left|d\left(x_{1}, x_{2}\right)\right| .
\end{aligned}
$$

Thus

$$
\left|d\left(x_{1}, x_{2}\right)\right| \leqslant k\left|d\left(x_{0}, x_{1}\right)\right|,
$$

where $k=\frac{\lambda}{1-\mu}<1$. From (2.3), we have

$$
\left|d\left(x_{1}, x_{2}\right)\right| \leqslant k\left|d\left(x_{0}, x_{1}\right)\right| \leqslant k(1-k)|r| .
$$

Consider

$$
\left|d\left(x_{0}, x_{2}\right)\right| \leqslant\left|d\left(x_{0}, x_{1}\right)\right|+\left|d\left(x_{1}, x_{2}\right)\right| \leqslant(1-k)|r|+k(1-k)|r|=(1-k)(1+k)|r| \leqslant\left(1-k^{2}\right)|r| .
$$

Thus $x_{2} \in \bar{B}\left(x_{0}, r\right)$. Since $\alpha\left(x_{1}, x_{2}\right) \geqslant 1$ and the pair $\{S, T\}$ is coupled $\alpha^{*}$-admissible, so $a^{*}\left(T x_{1}, S x_{2}\right) \geqslant 1$. From (2.1), we get

$$
\lambda d\left(x_{1}, x_{2}\right)+\frac{\mu d\left(x_{1}, T x_{1}\right) d\left(x_{2}, S x_{2}\right)+\gamma d\left(x_{1}, S x_{2}\right) d\left(x_{2}, T x_{1}\right)}{1+d\left(x_{1}, x_{2}\right)} \in a^{*}\left(T x_{1}, S x_{2}\right) s\left(T x_{1}, S x_{2}\right) .
$$

By Lemma 2.1 (3), we have

$$
\lambda d\left(x_{1}, x_{2}\right)+\frac{\mu d\left(x_{1}, T x_{1}\right) d\left(x_{2}, S x_{2}\right)+\gamma d\left(x_{1}, S x_{2}\right) d\left(x_{2}, T x_{1}\right)}{1+d\left(x_{1}, x_{2}\right)} \in a^{*}\left(T x_{1}, S x_{2}\right) s\left(x_{2}, S x_{2}\right) .
$$

By the definition there exists some $x_{3} \in S x_{2}$, such that

$$
\lambda d\left(x_{1}, x_{2}\right)+\frac{\mu d\left(x_{1}, T x_{1}\right) d\left(x_{2}, S x_{2}\right)+\gamma d\left(x_{1}, S x_{2}\right) d\left(x_{2}, T x_{1}\right)}{1+d\left(x_{1}, x_{2}\right)} \in a^{*}\left(T x_{1}, S x_{2}\right) s\left(d\left(x_{2}, x_{3}\right)\right) .
$$

By the definition and Lemma 2.1 (4), we get

$$
a^{*}\left(T x_{1}, S x_{2}\right) d\left(x_{2}, x_{3}\right) \preceq \lambda d\left(x_{1}, x_{2}\right)+\frac{\mu d\left(x_{1}, T x_{1}\right) d\left(x_{2}, S x_{2}\right)+\gamma d\left(x_{1}, S x_{2}\right) d\left(x_{2}, T x_{1}\right)}{1+d\left(x_{1}, x_{2}\right)} .
$$

By using the greatest lower bound property (g.l.b property) of $S$ and $T$, we get

$$
a^{*}\left(T x_{1}, S x_{2}\right) d\left(x_{2}, x_{3}\right) \preceq \lambda d\left(x_{1}, x_{2}\right)+\frac{\mu d\left(x_{1}, x_{2}\right) d\left(x_{2}, x_{3}\right)+\gamma d\left(x_{1}, x_{3}\right) d\left(x_{2}, x_{2}\right)}{1+d\left(x_{1}, x_{2}\right)} .
$$

Hence

$$
0 \prec \mathrm{d}\left(\mathrm{x}_{2}, \mathrm{x}_{3}\right) \preceq \mathrm{a}^{*}\left(\mathrm{~T} x_{1}, S x_{2}\right) \mathrm{d}\left(\mathrm{x}_{2}, \mathrm{x}_{3}\right) \preceq \lambda \mathrm{d}\left(\mathrm{x}_{1}, \mathrm{x}_{2}\right)+\frac{\mu \mathrm{d}\left(\mathrm{x}_{1}, \mathrm{x}_{2}\right) \mathrm{d}\left(\mathrm{x}_{2}, \mathrm{x}_{3}\right)}{1+\mathrm{d}\left(\mathrm{x}_{1}, \mathrm{x}_{2}\right)},
$$

which implies that

$$
\left|d\left(x_{2}, x_{3}\right)\right| \leqslant \lambda\left|d\left(x_{1}, x_{2}\right)\right|+\mu\left|d\left(x_{2}, x_{3}\right)\right| \frac{\left|d\left(x_{1}, x_{2}\right)\right|}{\left|1+d\left(x_{1}, x_{2}\right)\right|}
$$


Thus

$$
\left|d\left(x_{2}, x_{3}\right)\right| \leqslant k\left|d\left(x_{1}, x_{2}\right)\right|,
$$

where $k=\frac{\lambda}{1-\mu}<1$. As

$$
\left|d\left(x_{0}, x_{3}\right)\right| \leqslant\left|d\left(x_{0}, x_{1}\right)\right|+\left|d\left(x_{1}, x_{2}\right)\right|+\left|d\left(x_{2}, x_{3}\right)\right| \leqslant(1-k)|r|+k(1-k)|r|+k^{2}(1-k)|r|=\left(1-k^{3}\right)|r| \leqslant|r|,
$$

so $x_{3} \in \bar{B}\left(x_{0}, r\right)$. Continuing in this way, we can construct a sequence $\left\{x_{n}\right\}$ in $\bar{B}\left(x_{0}, r\right)$ such that for $n=$ $0,1,2, \ldots$

$$
\alpha\left(x_{2 n}, x_{2 n+1}\right) \geqslant 1 \text { and } \alpha\left(x_{2 n+1}, x_{2 n+2}\right) \geqslant 1
$$

with

$$
\left|d\left(x_{2 n}, x_{2 n+1}\right)\right| \leqslant k^{2 n}\left|d\left(x_{0}, x_{1}\right)\right| \text { and }\left|d\left(x_{2 n+1}, x_{2 n+2}\right)\right| \leqslant k^{2 n+1}\left|d\left(x_{0}, x_{1}\right)\right|,
$$

where $k=\frac{\lambda}{1-\mu}<1$ and $x_{2 n+1} \in S x_{2 n}$ and $x_{2 n+2} \in T x_{2 n+1}$.

Now inductively, we can construct a sequence $\left\{x_{n}\right\}$ in $X$ such that for $n=0,1,2, \ldots$

$$
\alpha\left(x_{n}, x_{n+1}\right) \geqslant 1 \text { and }\left|d\left(x_{n}, x_{n+1}\right)\right| \leqslant k^{n}\left|d\left(x_{0}, x_{1}\right)\right| .
$$

Without loss of generality assume that we take $m>n$. Then by (2.4) and the triangle inequality, we get

$$
\begin{aligned}
\left|d\left(x_{n}, x_{m}\right)\right| & \leqslant\left|d\left(x_{n}, x_{n+1}\right)\right|+\left|d\left(x_{n+1}, x_{n+2}\right)\right|+\cdots+\left|d\left(x_{m-1}, x_{m}\right)\right| \\
& \leqslant\left[k^{n}+k^{n+1}+\cdots+k^{m-1}\right]\left|d\left(x_{0}, x_{1}\right)\right| \leqslant\left[\frac{k^{n}}{1-k}\right]\left|d\left(x_{0}, x_{1}\right)\right|
\end{aligned}
$$

and so

$$
\left|d\left(x_{n}, x_{m}\right)\right| \leqslant \frac{k^{n}}{1-k}\left|d\left(x_{0}, x_{1}\right)\right| \longrightarrow 0 \text { as } m, n \longrightarrow \infty .
$$

This implies that $\left\{x_{n}\right\}$ is a Cauchy sequence in $\bar{B}\left(x_{0}, r\right)$. Since $X$ is complete and $\bar{B}\left(x_{0}, r\right)$ is a closed subspace of $X$, so there exists $u \in \bar{B}\left(x_{0}, r\right)$ such that $x_{n} \longrightarrow u$ as $n \longrightarrow \infty$. We now show that $u \in T u$ and $u \in S u$. Since $\alpha\left(x_{2 n}, u\right) \geqslant 1$ for all $n$ and the pair $\{S, T\}$ is coupled $\alpha^{*}$-admissible, so $\alpha^{*}\left(S x_{2 n}, T u\right) \geqslant 1$ for all $n$. From (2.1), we have

$$
\lambda d\left(x_{2 n}, u\right)+\frac{\mu d\left(x_{2 n}, S x_{2 n}\right) d(u, T u)+\gamma d\left(u, S x_{2 n}\right) d\left(x_{2 n}, T u\right)}{1+d\left(x_{2 n}, u\right)} \in \alpha^{*}\left(S x_{2 n}, T u\right) s\left(S x_{2 n}, T u\right) .
$$

By Lemma 2.1 (3), we have

$$
\lambda d\left(x_{2 n}, u\right)+\frac{\mu d\left(x_{2 n}, S x_{2 n}\right) d(u, T u)+\gamma d\left(u, S x_{2 n}\right) d\left(x_{2 n}, T u\right)}{1+d\left(x_{2 n}, u\right)} \in \alpha^{*}\left(S x_{2 n}, T u\right) s\left(x_{2 n+1}, T u\right) .
$$

By the definition there exists some $u_{n} \in T u$ such that

$$
\lambda d\left(x_{2 n}, u\right)+\frac{\mu d\left(x_{2 n}, S x_{2 n}\right) d(u, T u)+\gamma d\left(u, S x_{2 n}\right) d\left(x_{2 n}, T u\right)}{1+d\left(x_{2 n}, u\right)} \in \alpha^{*}\left(S x_{2 n}, T u\right) s\left(d\left(x_{2 n+1}, u_{n}\right)\right) .
$$

By the definition and Lemma 2.1 (4), we get

$$
\alpha^{*}\left(S x_{2 n}, T u\right) d\left(x_{2 n+1}, u_{n}\right) \preceq \lambda d\left(x_{2 n}, u\right)+\frac{\mu d\left(x_{2 n}, S x_{2 n}\right) d(u, T u)+\gamma d\left(u, S x_{2 n}\right) d\left(x_{2 n}, T u\right)}{1+d\left(x_{2 n}, u\right)} .
$$

By using the greatest lower bound property (g.l.b property) of $S$ and $T$, we have

$$
\alpha^{*}\left(S x_{2 n}, T u\right) d\left(x_{2 n+1}, u_{n}\right) \preceq \lambda d\left(x_{2 n}, u\right)+\frac{\mu d\left(x_{2 n}, x_{2 n+1}\right) d\left(u, u_{n}\right)+\gamma d\left(u, x_{2 n+1}\right) d\left(x_{2 n}, u_{n}\right)}{1+d\left(x_{2 n}, u\right)} .
$$


Since $\alpha^{*}\left(S x_{2 n}, T u\right) \geqslant 1$, so we get

$$
0 \prec d\left(x_{2 n+1}, u_{n}\right) \preceq \lambda d\left(x_{2 n}, u\right)+\frac{\mu d\left(x_{2 n}, x_{2 n+1}\right) d\left(u, u_{n}\right)+\gamma d\left(u, x_{2 n+1}\right) d\left(x_{2 n}, u_{n}\right)}{1+d\left(x_{2 n}, u\right)} .
$$

Since

$$
d\left(u, u_{n} \preceq d\left(u, x_{2 n+1}\right)+d\left(x_{2 n+1}, u_{n}\right),\right.
$$

using (2.5), we get

$$
\begin{aligned}
d\left(u, u_{n}\right) & \preceq d\left(u, x_{2 n+1}\right)+\lambda d\left(x_{2 n}, u\right)+\frac{\mu d\left(x_{2 n}, x_{2 n+1}\right) d\left(u, u_{n}\right)+\gamma d\left(u, x_{2 n+1}\right) d\left(x_{2 n}, u_{n}\right)}{1+d\left(x_{2 n}, u\right)}, \\
\mid d\left(u, u_{n}\right) & \leqslant\left|d\left(u, x_{2 n+1}\right)\right|+\lambda\left|d\left(u, x_{2 n+1}\right)\right|+\frac{\mu\left|d\left(x_{2 n}, x_{2 n+1}\right)\right|\left|d\left(u, u_{n}\right)\right|+\gamma\left|d\left(u, x_{2 n+1}\right)\right|\left|d\left(x_{2 n}, u_{n}\right)\right|}{\left|1+d\left(x_{2 n}, u\right)\right|} .
\end{aligned}
$$

Taking the limit as $n \longrightarrow \infty$, we get $\mid d\left(u, u_{n}\right) \longrightarrow 0$ as $n \longrightarrow \infty$. By Lemma 1.2 we have $u_{n} \longrightarrow u$ as $n \longrightarrow \infty$. Since $T u$ is closed, so $u \in T u$. Similarly, it follows that $u \in S u$. Thus $S$ and $T$ have a common fixed point.

Remark 2.10. The conclusion remains true if condition (2.2) is replaced by

$$
(1-k) r \in s\left(x_{0}, T x_{0}\right) .
$$

By setting $\gamma=0$ in Theorem 2.9, we get the following corollary.

Corollary 2.11. Let $S, T: X \longrightarrow \mathrm{CB}(\mathrm{X})$ be coupled $\alpha^{*}$-admissible mappings with g.l.b property on complete complex-valued metric space $(\mathrm{X}, \mathrm{d}), \mathrm{x}_{0} \in \mathrm{X}$ and $0 \prec \mathrm{r} \in \mathbb{C}$. If $\mathrm{S}$ and $\mathrm{T}$ satisfy

$$
\lambda d(x, y)+\frac{\mu d(x, S x) d(y, T y)}{1+d(x, y)} \in \alpha^{*}(S x, T y) s(S x, T y)
$$

for all $x, y \in \bar{B}\left(x_{0}, r\right)$, then

$$
(1-k) r \in s\left(x_{0}, S x_{0}\right),
$$

where $\lambda$ and $\mu$ are non-negative real numbers with $k=\frac{\lambda}{1-\mu}<1$. Suppose that there exist $x_{0} \in X, x_{1} \in \bar{B}\left(x_{0}, r\right)$ such that $\alpha\left(x_{0}, x_{1}\right) \geqslant 1$. Assume that if $\left\{x_{n}\right\}$ is a sequence in $\bar{B}\left(x_{0}, r\right)$ such that $\alpha\left(x_{n}, x_{n+1}\right) \geqslant 1$ and $x_{n} \rightarrow u$ as $\mathrm{n} \rightarrow+\infty$, then $\alpha\left(\mathrm{x}_{\mathrm{n}}, \mathrm{u}\right) \geqslant 1$ for all $\mathrm{n}$. Then, there exists a point $\mathrm{x}^{*}$ in $\overline{\mathrm{B}}\left(\mathrm{x}_{0}, \mathrm{r}\right)$ such that $\mathrm{x}^{*} \in \mathrm{S} \mathrm{x}^{*} \cap \mathrm{T} \mathrm{x}^{*}$.

By setting $S=T$ in Theorem 2.9, we get the following corollary.

Corollary 2.12. Let $\mathrm{T}: \mathrm{X} \longrightarrow \mathrm{CB}(\mathrm{X})$ be $\alpha^{*}$-admissible mapping with g.l.b property on complete complex-valued metric space $(\mathrm{X}, \mathrm{d}), \mathrm{x}_{0} \in \mathrm{X}$ and $0 \prec \mathrm{r} \in \mathbb{C}$. If $\mathrm{T}$ satisfies

$$
\lambda d(x, y)+\frac{\mu d(x, T x) d(y, T y)+\gamma d(y, T x) d(x, T y)}{1+d(x, y)} \in \alpha^{*}(T x, T y) s(T x, T y)
$$

for all $x, y \in \overline{\mathrm{B}}\left(\mathrm{x}_{0}, \mathrm{r}\right)$, then

$$
(1-k) r \in s\left(x_{0}, T x_{0}\right),
$$

where $\lambda, \mu$, and $\gamma$ are non-negative real numbers with $k=\frac{\lambda}{1-\mu}<1$. Suppose that there exist $x_{0} \in X, x_{1} \in \bar{B}\left(x_{0}, r\right)$ such that $\alpha\left(x_{0}, x_{1}\right) \geqslant 1$. Assume that if $\left\{x_{n}\right\}$ is a sequence in $\bar{B}\left(x_{0}, r\right)$ such that $\alpha\left(x_{n}, x_{n+1}\right) \geqslant 1$ and $x_{n} \rightarrow u$ as $\mathrm{n} \rightarrow+\infty$, then $\alpha\left(x_{n}, u\right) \geqslant 1$ for all $n$. Then, there exists a point $x^{*}$ in $\bar{B}\left(x_{0}, r\right)$ such that $x^{*} \in T x^{*}$.

By setting $\gamma=\mu=0$ in Theorem 2.9, we get the following corollary. 
Corollary 2.13. Let $\mathrm{S}, \mathrm{T}: \mathrm{X} \longrightarrow \mathrm{CB}(\mathrm{X})$ be coupled $\alpha^{*}$-admissible mappings with g.l.b property on complete complex-valued metric space $(X, \mathrm{~d}), \mathrm{x}_{0} \in \mathrm{X}$ and $0 \prec \mathrm{r} \in \mathbb{C}$. If $\mathrm{S}$ and $\mathrm{T}$ satisfy

$$
\lambda d(x, y) \in \alpha^{*}(S x, T y) s(S x, T y)
$$

for all $x, y \in \overline{\mathrm{B}}\left(\mathrm{x}_{0}, \mathrm{r}\right)$, then

$$
(1-k) r \in s\left(x_{0}, S x_{0}\right),
$$

where $\lambda$ is non-negative real number with $\mathrm{k}=\lambda<1$. Suppose that there exist $\mathrm{x}_{0} \in \mathrm{X}, \mathrm{x}_{1} \in \overline{\mathrm{B}}\left(\mathrm{x}_{0}, \mathrm{r}\right)$ such that $\alpha\left(x_{0}, x_{1}\right) \geqslant 1$. Assume that if $\left\{x_{n}\right\}$ is a sequence in $\bar{B}\left(x_{0}, r\right)$ such that $\alpha\left(x_{n}, x_{n+1}\right) \geqslant 1$ and $x_{n} \rightarrow u$ as $n \rightarrow+\infty$, then $\alpha\left(x_{n}, u\right) \geqslant 1$ for all $n$. Then, there exists a point $x^{*}$ in $\bar{B}\left(x_{0}, r\right)$ such that $x^{*} \in S x^{*} \cap T x^{*}$.

Now we give an example to support our above result.

Example 2.14. Let $X=[0, \infty)$. Define $d: X \times X \rightarrow \mathbb{C}$ by

$$
d(x, y)=|x-y| e^{i \theta}, \theta=\tan ^{-1}\left|\frac{y}{x}\right| .
$$

Then $(X, d)$ is a complex-valued metric space. Considering $x_{0}=\frac{1}{2}$ and $r=\frac{1}{2}$, then $\bar{B}\left(x_{0}, r\right)=[0,1]$ and

$$
\alpha(x, y)= \begin{cases}1, & \text { if } x, y \in[0,1] \\ \frac{3}{2}, & \text { otherwise }\end{cases}
$$

Consider the mappings $S, T: X \rightarrow C B(X)$ defined by

$$
S x=\left\{\begin{array}{l}
{\left[0, \frac{1}{5} x\right], \quad \text { if } x, y \in[0,1]} \\
{[2 x, 3 x], \quad \text { otherwise }}
\end{array}\right.
$$

and

$$
T x=\left\{\begin{array}{l}
{\left[0, \frac{1}{10} x\right], \quad \text { if } x, y \in[0,1]} \\
{[3 x, 4 x], \quad \text { otherwise. }}
\end{array}\right.
$$

We prove that all the conditions of our Corollary 2.13 are satisfied only for $x, y \in \bar{B}\left(x_{0}, r\right)$.

If $x, y \in[0,1]$. The contractive condition of main theorem is trivial for the case when $x=y=0$. Suppose without any loss of generality that all $x, y$ are nonzero and $x<y$. Then

$$
\begin{aligned}
& d(x, y)=|y-x| e^{i \theta}, \quad d(x, S x)=\left|x-\frac{x}{5}\right| e^{i \theta}, \quad d(y, T y)=\left|y-\frac{y}{10}\right| e^{i \theta}, \\
& d(y, S x)=\left|y-\frac{x}{5}\right| e^{i \theta}, \quad d(x, T y)=\left|x-\frac{y}{10}\right| e^{i \theta},
\end{aligned}
$$

and

$$
s(S x, T y)=s\left(\left|\frac{x}{5}-\frac{y}{10}\right| e^{i \theta}\right) .
$$

Clearly for $\lambda=\frac{1}{5}$, we have

$$
\left|\frac{x}{5}-\frac{y}{10}\right| \leqslant \frac{1}{5}|y-x|
$$

Thus

$$
\lambda d(x, y) \in \alpha_{*}(S x, T y) s(S x, T y) .
$$

Hence all the conditions of our main theorem are satisfied and 0 is a common fixed point of $S$ and $T$.

Now we prove that the contractive condition is not satisfied for $x, y \notin \bar{B}\left(x_{0}, r\right)$ and for any value of $\lambda$. We suppose $x=2$ and $y=3$, then

$$
\alpha_{*}(S x, T y) s(S x, T y)=8 e^{i \theta} \succ e^{i \theta} \succ \lambda d(x, y)
$$

so

$$
\lambda d(x, y) \notin \alpha_{*}(S x, T y) s(S x, T y)
$$


Theorem 2.15. Let $S, T: X \longrightarrow \mathrm{CB}(\mathrm{X})$ be coupled $\alpha^{*}$-admissible mappings with g.l.b property on complete complex-valued metric space $(\mathrm{X}, \mathrm{d}), \mathrm{x}_{0} \in \mathrm{X}$ and $0 \prec \mathrm{r} \in \mathbb{C}$. If $\mathrm{S}$ and $\mathrm{T}$ satisfy

$$
\operatorname{ad}(x, S x)+b d(y, T y)+c \frac{d(x, S x) d(y, T y)}{1+d(x, y)} \in \alpha^{*}(S x, T y) s(S x, T y)
$$

for all $x, y \in \overline{\mathrm{B}}\left(\mathrm{x}_{0}, \mathrm{r}\right)$, then

$$
(1-l) r \in s\left(x_{0}, S x_{0}\right),
$$

where $\mathrm{a}, \mathrm{b}$, and $\mathrm{c}$ are non-negative real numbers with $\mathrm{l}=\frac{\mathrm{a}}{1-\mathrm{b}-\mathrm{c}}<1$. Suppose that there exist $\mathrm{x}_{0} \in \mathrm{X}, \mathrm{x}_{1} \in \overline{\mathrm{B}}\left(\mathrm{x}_{0}, \mathrm{r}\right)$ such that $\alpha\left(x_{0}, x_{1}\right) \geqslant 1$. Assume that if $\left\{x_{n}\right\}$ is a sequence in $\bar{B}\left(x_{0}, r\right)$ such that $\alpha\left(x_{n}, x_{n+1}\right) \geqslant 1$ and $x_{n} \rightarrow v$ as $\mathrm{n} \rightarrow+\infty$, then $\alpha\left(x_{n}, v\right) \geqslant 1$ for all $n$. Then, there exists a point $x^{*}$ in $\bar{B}\left(x_{0}, r\right)$ such that $x^{*} \in S x^{*} \cap T x^{*}$.

Proof. Let $\mathrm{x}_{0}$ be an arbitrary point in X. From (2.7), one can easily prove that

$$
\left|d\left(x_{0}, x_{1}\right)\right| \leqslant(1-l)|r| .
$$

Thus $x_{1} \in \bar{B}\left(x_{0}, r\right)$. Since $\alpha\left(x_{0}, x_{1}\right) \geqslant 1$ and the pair $\{S, T\}$ is coupled $\alpha^{*}$-admissible, so $a^{*}\left(S x_{0}, T x_{1}\right) \geqslant 1$. From (2.6), we get

$$
a d\left(x_{0}, S x_{0}\right)+b d\left(x_{1}, T x_{1}\right)+c \frac{d\left(x_{0}, S x_{0}\right) d\left(x_{1}, T x_{1}\right)}{1+d\left(x_{0}, x_{1}\right)} \in a^{*}\left(S x_{0}, T x_{1}\right) s\left(S x_{0}, T x_{1}\right) .
$$

By Lemma 2.1 (3), we have

$$
\operatorname{ad}\left(x_{0}, S x_{0}\right)+b d\left(x_{1}, T x_{1}\right)+c \frac{d\left(x_{0}, S x_{0}\right) d\left(x_{1}, T x_{1}\right)}{1+d\left(x_{0}, x_{1}\right)} \in a^{*}\left(S x_{0}, T x_{1}\right) s\left(x_{1}, T x_{1}\right)
$$

By the definition, we can take $x_{2} \in T x_{1}$ such that

$$
a d\left(x_{0}, S x_{0}\right)+b d\left(x_{1}, T x_{1}\right)+c \frac{d\left(x_{0}, S x_{0}\right) d\left(x_{1}, T x_{1}\right)}{1+d\left(x_{0}, x_{1}\right)} \in a^{*}\left(S x_{0}, T x_{1}\right) s\left(d\left(x_{1}, x_{2}\right)\right) .
$$

By the definition and Lemma 2.1 (4), we get

$$
a^{*}\left(S x_{0}, T x_{1}\right) d\left(x_{1}, x_{2}\right) \preceq a d\left(x_{0}, S x_{0}\right)+b d\left(x_{1}, T x_{1}\right)+c \frac{d\left(x_{0}, S x_{0}\right) d\left(x_{1}, T x_{1}\right)}{1+d\left(x_{0}, x_{1}\right)} .
$$

By using the greatest lower bound property (g.l.b property) of $S$ and $T$, we get

$$
a^{*}\left(S x_{0}, T x_{1}\right) d\left(x_{1}, x_{2}\right) \preceq a d\left(x_{0}, x_{1}\right)+b d\left(x_{1}, x_{2}\right)+c \frac{d\left(x_{0}, x_{1}\right) d\left(x_{1}, x_{2}\right)}{1+d\left(x_{0}, x_{1}\right)} .
$$

Hence

$$
0 \prec d\left(x_{1}, x_{2}\right) \preceq \operatorname{ad}\left(x_{0}, x_{1}\right)+b d\left(x_{1}, x_{2}\right)+c \frac{d\left(x_{0}, x_{1}\right) d\left(x_{1}, x_{2}\right)}{1+d\left(x_{0}, x_{1}\right)}
$$

which implies that

$$
\left|d\left(x_{1}, x_{2}\right)\right| \leqslant a\left|d\left(x_{0}, x_{1}\right)\right|+b\left|d\left(x_{1}, x_{2}\right)\right|+c \frac{\left|d\left(x_{0}, x_{1}\right)\right|\left|d\left(x_{1}, x_{2}\right)\right|}{\left|1+d\left(x_{0}, x_{1}\right)\right|}
$$

since $\left|d\left(x_{0}, x_{1}\right)\right|<\left|1+d\left(x_{0}, x_{1}\right)\right|$, so we have

$$
\left|d\left(x_{1}, x_{2}\right)\right| \leqslant a\left|d\left(x_{0}, x_{1}\right)\right|+b\left|d\left(x_{1}, x_{2}\right)\right|+c\left|d\left(x_{1}, x_{2}\right)\right|, \quad\left|d\left(x_{1}, x_{2}\right)\right| \leqslant l\left|d\left(x_{0}, x_{1}\right)\right|,
$$


where $l=\frac{a}{(1-b-c)}<1$. From (2.8), we get

$$
\left|d\left(x_{1}, x_{2}\right)\right| \leqslant l(1-l)|r| .
$$

Consider

$$
\left|\mathrm{d}\left(\mathrm{x}_{0}, \mathrm{x}_{2}\right)\right| \leqslant\left|\mathrm{d}\left(\mathrm{x}_{0}, \mathrm{x}_{1}\right)\right|+\left|\mathrm{d}\left(\mathrm{x}_{1}, \mathrm{x}_{2}\right)\right| \leqslant(1-l)|\mathrm{r}|+\mathrm{k}(1-l)|\mathrm{r}|=(1-l)(1+l)|\mathrm{r}| \leqslant\left(1-\mathrm{l}^{2}\right)|\mathrm{r}| .
$$

Thus $x_{2} \in \bar{B}\left(x_{0}, r\right)$. Since $\alpha\left(x_{1}, x_{2}\right) \geqslant 1$ and the pair $\{S, T\}$ is coupled $\alpha^{*}$-admissible, so $a^{*}\left(T x_{1}, S x_{2}\right) \geqslant 1$. From (2.6), we get

$$
a d\left(x_{1}, T x_{1}\right)+b d\left(x_{2}, S x_{2}\right)+c \frac{d\left(x_{1}, T x_{1}\right) d\left(x_{2}, S x_{2}\right)}{1+d\left(x_{1}, x_{2}\right)} \in a^{*}\left(T x_{1}, S x_{2}\right) s\left(T x_{1}, S x_{2}\right) .
$$

By Lemma 2.1 (3), we have

$$
a d\left(x_{1}, T x_{1}\right)+b d\left(x_{2}, S x_{2}\right)+c \frac{d\left(x_{1}, T x_{1}\right) d\left(x_{2}, S x_{2}\right)}{1+d\left(x_{1}, x_{2}\right)} \in a^{*}\left(T x_{1}, S x_{2}\right) s\left(x_{2}, S x_{2}\right) .
$$

By the definition there exists some $x_{3} \in S x_{2}$, such that

$$
a d\left(x_{1}, T x_{1}\right)+b d\left(x_{2}, S x_{2}\right)+c \frac{d\left(x_{1}, T x_{1}\right) d\left(x_{2}, S x_{2}\right)}{1+d\left(x_{1}, x_{2}\right)} \in a^{*}\left(T x_{1}, S x_{2}\right) s\left(d\left(x_{2}, x_{3}\right)\right) .
$$

By the definition and Lemma 2.1 (4), we get

$$
a^{*}\left(T x_{1}, S x_{2}\right) d\left(x_{2}, x_{3}\right) \preceq a d\left(x_{1}, T x_{1}\right)+b d\left(x_{2}, S x_{2}\right)+c \frac{d\left(x_{1}, T x_{1}\right) d\left(x_{2}, S x_{2}\right)}{1+d\left(x_{1}, x_{2}\right)} .
$$

By using the greatest lower bound property (g.l.b property) of $S$ and $T$, we get

$$
a^{*}\left(T x_{1}, S x_{2}\right) d\left(x_{2}, x_{3}\right) \preceq a d\left(x_{1}, x_{2}\right)+b d\left(x_{2}, x_{3}\right)+c \frac{d\left(x_{1}, x_{2}\right) d\left(x_{2}, x_{3}\right)}{1+d\left(x_{1}, x_{2}\right)} .
$$

Hence

$$
0 \prec d\left(x_{2}, x_{3}\right) \preceq \operatorname{ad}\left(x_{1}, x_{2}\right)+b d\left(x_{2}, x_{3}\right)+c \frac{d\left(x_{1}, x_{2}\right) d\left(x_{2}, x_{3}\right)}{1+d\left(x_{1}, x_{2}\right)},
$$

which implies that

$$
\left|d\left(x_{2}, x_{3}\right)\right| \leqslant a\left|d\left(x_{1}, x_{2}\right)\right|+b\left|d\left(x_{2}, x_{3}\right)\right|+c \frac{\left|d\left(x_{1}, x_{2}\right)\right|}{\left|1+d\left(x_{1}, x_{2}\right)\right|}\left|d\left(x_{2}, x_{3}\right)\right| .
$$

Thus

$$
\left|d\left(x_{2}, x_{3}\right)\right| \leqslant l\left|d\left(x_{1}, x_{2}\right)\right|,
$$

where $l=\frac{a}{1-b-c}<1$. Consider

$$
\left|d\left(x_{0}, x_{3}\right)\right| \leqslant\left|d\left(x_{0}, x_{1}\right)\right|+\left|d\left(x_{1}, x_{2}\right)\right|+\left|d\left(x_{2}, x_{3}\right)\right| \leqslant(1-l)|r|+l(1-l)|r|+l^{2}(1-l)|r|=\left(1-l^{3}\right)|r| \leqslant|r| .
$$

So $x_{3} \in \bar{B}\left(x_{0}, r\right)$. Continuing in this way, we can construct a sequence $\left\{x_{n}\right\}$ in $\bar{B}\left(x_{0}, r\right)$ such that for $n=$ $0,1,2, \ldots$

$$
\alpha\left(x_{2 n}, x_{2 n+1}\right) \geqslant 1 \text { and } \alpha\left(x_{2 n+1}, x_{2 n+2}\right) \geqslant 1
$$

with

$$
\left|d\left(x_{2 n}, x_{2 n+1}\right)\right| \leqslant l^{2 n}\left|d\left(x_{0}, x_{1}\right)\right| \text { and }\left|d\left(x_{2 n+1}, x_{2 n+2}\right)\right| \leqslant l^{2 n+1}\left|d\left(x_{0,}, x_{1}\right)\right|,
$$

where $l=\frac{a}{1-b-c}<1$ and $x_{2 n+1} \in S x_{2 n}$ and $x_{2 n+2} \in T x_{2 n+1}$. 
Now inductively, we can construct a sequence $\left\{x_{n}\right\}$ in $X$ such that for $n=0,1,2, \ldots$

$$
\alpha\left(x_{n}, x_{n+1}\right) \geqslant 1 \text { and }\left|d\left(x_{n}, x_{n+1}\right)\right| \leqslant l^{n}\left|d\left(x_{0}, x_{1}\right)\right| .
$$

The proof of $\left\{x_{n}\right\}$ is a Cauchy sequence in $\bar{B}\left(x_{0}, r\right)$ is similar as in Theorem 2.9. Since $X$ is complete and $\overline{\mathrm{B}}\left(x_{0}, r\right)$ is a closed subspace of $X$, so there exists $v \in \bar{B}\left(x_{0}, r\right)$ such that $x_{n} \longrightarrow u$ as $n \longrightarrow \infty$. We now show that $v \in T v$ and $v \in S v$. Since $\alpha\left(x_{2 n}, v\right) \geqslant 1$ for all $n$ and the pair $\{S, T\}$ is coupled $\alpha^{*}$-admissible, so $\alpha^{*}\left(S x_{2 n}, T v\right) \geqslant 1$ for all $n$. From (2.6), we get

$$
a d\left(x_{2 n}, S x_{2 n}\right)+b d(v, T v)+c \frac{d\left(x_{2 n}, S x_{2 n}\right) d(v, T v)}{1+d\left(x_{2 n}, v\right)} \in \alpha^{*}\left(S x_{2 n}, T v\right) s\left(S x_{2 n}, T v\right) .
$$

By Lemma 2.1 (3), we have

$$
a d\left(x_{2 n}, S x_{2 n}\right)+b d(v, T v)+c \frac{d\left(x_{2 n}, S x_{2 n}\right) d(v, T v)}{1+d\left(x_{2 n}, v\right)} \in \alpha^{*}\left(S x_{2 n}, T v\right) s\left(x_{2 n+1}, T v\right) .
$$

By the definition, there exists some $v_{n} \in T v$ such that

$$
a d\left(x_{2 n}, S x_{2 n}\right)+b d(v, T v)+c \frac{d\left(x_{2 n}, S x_{2 n}\right) d(v, T v)}{1+d\left(x_{2 n}, v\right)} \in \alpha^{*}\left(S x_{2 n}, T v\right) s\left(d\left(x_{2 n+1}, v_{n}\right)\right)
$$

By the definition and Lemma 2.1 (4), we get

$$
\alpha^{*}\left(S x_{2 n}, T v\right) d\left(x_{2 n+1}, v_{n}\right) \preceq \operatorname{ad}\left(x_{2 n}, S x_{2 n}\right)+b d(v, T v)+c \frac{d\left(x_{2 n}, S x_{2 n}\right) d(v, T v)}{1+d\left(x_{2 n}, v\right)} .
$$

By using the greatest lower bound property (g.l.b property) of $S$ and $T$, we get

$$
\alpha^{*}\left(S x_{2 n}, T v\right) d\left(x_{2 n+1}, v_{n}\right) \preceq \operatorname{ad}\left(x_{2 n}, x_{2 n+1}\right)+b d\left(v, v_{n}\right)+c \frac{d\left(x_{2 n}, x_{2 n+1}\right) d\left(v, v_{n}\right)}{1+d\left(x_{2 n}, v\right)} .
$$

Hence

$$
0 \prec d\left(x_{2 n+1}, v_{n}\right) \preceq a d\left(x_{2 n}, x_{2 n+1}\right)+b d\left(v, v_{n}\right)+c \frac{d\left(x_{2 n}, x_{2 n+1}\right) d\left(v, v_{n}\right)}{1+d\left(x_{2 n}, v\right)} .
$$

Now by using the triangular inequality, we get

$$
\begin{aligned}
d\left(v, v_{n}\right) \preceq & d\left(v, x_{2 n+1}\right)+d\left(x_{2 n+1}, v_{n}\right) \preceq d\left(v, x_{2 n+1}\right)+a d\left(x_{2 n}, x_{2 n+1}\right)+b d\left(v, v_{n}\right) \\
& +c \frac{d\left(x_{2 n}, x_{2 n+1}\right) d\left(v, v_{n}\right)}{1+d\left(x_{2 n}, v\right)}, \\
(1-b)\left|d\left(v, v_{n}\right)\right| \leqslant & \left|d\left(v, x_{2 n+1}\right)\right|+a\left|d\left(x_{2 n}, x_{2 n+1}\right)\right|+c\left|\frac{d\left(x_{2 n}, x_{2 n+1}\right) d\left(v, v_{n}\right)}{1+d\left(x_{2 n}, v\right)}\right|, \\
\left|d\left(v, v_{n}\right)\right| \leqslant & \frac{1}{(1-b)}\left|d\left(v, x_{2 n+1}\right)\right|+\frac{a}{(1-b)}\left|d\left(x_{2 n}, x_{2 n+1}\right)\right|+\frac{c}{(1-b)} \frac{\left|d\left(x_{2 n}, x_{2 n+1}\right)\right|\left|d\left(v, v_{n}\right)\right|}{\left|1+d\left(x_{2 n}, v\right)\right|} .
\end{aligned}
$$

By letting $n \longrightarrow \infty$ in above inequality, we get

$$
\left|\mathrm{d}\left(v, v_{\mathrm{n}}\right)\right| \longrightarrow 0 \text { as } \mathrm{n} \longrightarrow \infty \text {. }
$$

By Lemma 1.2, we have $v_{n} \longrightarrow v$ as $n \longrightarrow \infty$. Since Tv is closed, so $v \in T v$. Similarly, it follows that $v \in S v$. Thus $S$ and $T$ have a common fixed point.

By taking $\mathrm{c}=0$ in Theorem 2.15, we get the following corollary. 
Corollary 2.16. Let $\mathrm{S}, \mathrm{T}: \mathrm{X} \longrightarrow \mathrm{CB}(\mathrm{X})$ be coupled $\alpha^{*}$-admissible mappings with g.l.b property on complete complex-valued metric space $(\mathrm{X}, \mathrm{d}), \mathrm{x}_{0} \in \mathrm{X}$ and $0 \prec \mathrm{r} \in \mathbb{C}$. If $\mathrm{S}$ and $\mathrm{T}$ satisfy

$$
\operatorname{ad}(x, S x)+b d(y, T y) \in \alpha^{*}(S x, T y) s(S x, T y)
$$

for all $x, y \in \overline{\mathrm{B}}\left(\mathrm{x}_{0}, \mathrm{r}\right)$, then

$$
(1-l) r \in s\left(x_{0}, S x_{0}\right)
$$

where $\mathrm{a}$ and $\mathrm{b}$ are non-negative real numbers with $\mathrm{l}=\frac{\mathrm{a}}{1-\mathrm{b}}<1$. Suppose that there exist $\mathrm{x}_{0} \in \mathrm{X}, \mathrm{x}_{1} \in \overline{\mathrm{B}}\left(\mathrm{x}_{0}, \mathrm{r}\right)$ such that $\alpha\left(x_{0}, x_{1}\right) \geqslant 1$. Assume that if $\left\{x_{n}\right\}$ is a sequence in $\bar{B}\left(x_{0}, r\right)$ such that $\alpha\left(x_{n}, x_{n+1}\right) \geqslant 1$ and $x_{n} \rightarrow u$ as $\mathrm{n} \rightarrow+\infty$, then $\alpha\left(x_{n}, \mathrm{u}\right) \geqslant 1$ for all $n$. Then, there exists a point $x^{*}$ in $\overline{\mathrm{B}}\left(\mathrm{x}_{0}, \mathrm{r}\right)$ such that $x^{*} \in \mathrm{S} \mathrm{x}^{*} \cap T \mathrm{x}^{*}$.

By Taking $S=T$ in Theorem 2.15, we get the following corollary.

Theorem 2.17. Let $\mathrm{T}: \mathrm{X} \longrightarrow \mathrm{CB}(\mathrm{X})$ be $\alpha^{*}$-admissible mapping with g.l.b property on complete complex-valued metric space $(\mathrm{X}, \mathrm{d}), \mathrm{x}_{0} \in \mathrm{X}$ and $0 \prec \mathrm{r} \in \mathbb{C}$. If $\mathrm{T}$ satisfies

$$
a d(x, T x)+b d(y, T y)+c \frac{d(x, T x) d(y, T y)}{1+d(x, y)} \in \alpha^{*}(T x, T y) s(T x, T y)
$$

for all $x, y \in \overline{\mathrm{B}}\left(\mathrm{x}_{0}, \mathrm{r}\right)$, then

$$
(1-l) r \in s\left(x_{0}, T x_{0}\right),
$$

where $\mathrm{a}, \mathrm{b}$, and $\mathrm{c}$ are non-negative real numbers with $\mathrm{l}=\frac{\mathrm{a}}{1-\mathrm{b}-\mathrm{c}}<1$. Suppose that there exist $\mathrm{x}_{0} \in \mathrm{X}, \mathrm{x}_{1} \in \overline{\mathrm{B}}\left(\mathrm{x}_{0}, \mathrm{r}\right)$ such that $\alpha\left(x_{0}, x_{1}\right) \geqslant 1$. Assume that if $\left\{x_{n}\right\}$ is a sequence in $\bar{B}\left(x_{0}, r\right)$ such that $\alpha\left(x_{n}, x_{n+1}\right) \geqslant 1$ and $x_{n} \rightarrow u$ as $\mathrm{n} \rightarrow+\infty$, then $\alpha\left(x_{n}, \mathrm{u}\right) \geqslant 1$ for all $\mathrm{n}$. Then, there exists a point $x^{*}$ in $\overline{\mathrm{B}}\left(\mathrm{x}_{0}, \mathrm{r}\right)$ such that $\mathrm{x}^{*} \in \mathrm{T} \mathrm{x}^{*}$.

The following corollaries follow from Theorem 2.9.

Corollary 2.18. Let $\mathrm{S}, \mathrm{T}: \mathrm{X} \longrightarrow \mathrm{CB}(\mathrm{X})$ be coupled $\alpha^{*}$-admissible mappings on complete metric space $(\mathrm{X}, \mathrm{d})$, $x_{0} \in X$ and $0<r \in \mathbb{R}$. If $S$ and $T$ satisfy

$$
\alpha^{*}(S x, T y) H(S x, T y) \leqslant \lambda d(x, y)+\frac{\mu d(x, S x) d(y, T y)+\gamma d(y, S x) d(x, T y)}{1+d(x, y)}
$$

for all $x, y \in \bar{B}\left(x_{0}, r\right)$, then

$$
d\left(x_{0}, S x_{0}\right) \leqslant(1-k) r
$$

where $\lambda$ and $\mu$ are non-negative real numbers with $\mathrm{k}=\frac{\lambda}{1-\mu}<1$. Suppose that there exist $x_{0} \in X, x_{1} \in \overline{\mathrm{B}}\left(\mathrm{x}_{0}, \mathrm{r}\right)$ such that $\alpha\left(x_{0}, x_{1}\right) \geqslant 1$. Assume that if $\left\{x_{n}\right\}$ is a sequence in $\bar{B}\left(x_{0}, r\right)$ such that $\alpha\left(x_{n}, x_{n+1}\right) \geqslant 1$ and $x_{n} \rightarrow u$ as $\mathrm{n} \rightarrow+\infty$, then $\alpha\left(\mathrm{x}_{\mathrm{n}}, \mathrm{u}\right) \geqslant 1$ for all $\mathrm{n}$. Then, there exists a point $\mathrm{x}^{*}$ in $\overline{\mathrm{B}}\left(\mathrm{x}_{0}, \mathrm{r}\right)$ such that $\mathrm{x}^{*} \in \mathrm{S} \mathrm{x}^{*} \cap \mathrm{T} \mathrm{x}^{*}$.

Corollary 2.19. Let $\mathrm{T}: \mathrm{X} \longrightarrow \mathrm{CB}(\mathrm{X})$ be $\alpha^{*}$-admissible mapping on complete metric space $(\mathrm{X}, \mathrm{d}), \mathrm{x}_{0} \in \mathrm{X}$ and $0<r \in \mathbb{R}$. If $\mathrm{S}$ and $\mathrm{T}$ satisfy

$$
\alpha^{*}(T x, T y) H(T x, T y) \leqslant \lambda d(x, y)+\frac{\mu d(x, T x) d(y, T y)+\gamma d(y, T x) d(x, T y)}{1+d(x, y)}
$$

for all $x, y \in \bar{B}\left(x_{0}, r\right)$, then

$$
\mathrm{d}\left(\mathrm{x}_{0}, \mathrm{~T} \mathrm{x}_{0}\right) \leqslant(1-\mathrm{k}) \mathrm{r},
$$

where $\lambda$ and $\mu$ are non-negative real numbers with $\mathrm{k}=\frac{\lambda}{1-\mu}<1$. Suppose that there exist $x_{0} \in X, x_{1} \in \overline{\mathrm{B}}\left(x_{0}, r\right)$ such that $\alpha\left(x_{0}, x_{1}\right) \geqslant 1$. Assume that if $\left\{x_{n}\right\}$ is a sequence in $\bar{B}\left(x_{0}, r\right)$ such that $\alpha\left(x_{n}, x_{n+1}\right) \geqslant 1$ and $x_{n} \rightarrow u$ as $\mathrm{n} \rightarrow+\infty$, then $\alpha\left(x_{n}, \mathrm{u}\right) \geqslant 1$ for all $\mathrm{n}$. Then, there exists a point $x^{*}$ in $\overline{\mathrm{B}}\left(\mathrm{x}_{0}, \mathrm{r}\right)$ such that $\mathrm{x}^{*} \in \mathrm{T} \mathrm{x}^{*}$.

The following corollaries follow from Theorem 2.15. 
Corollary 2.20. Let $\mathrm{S}, \mathrm{T}: \mathrm{X} \longrightarrow \mathrm{CB}(\mathrm{X})$ be coupled $\alpha^{*}$-admissible mappings on complete metric space $(\mathrm{X}, \mathrm{d})$, $x_{0} \in X$ and $0<r \in \mathbb{R}$. If $S$ and $T$ satisfy

$$
\alpha^{*}(S x, T y) H(S x, T y) \leqslant a d(x, S x)+b d(y, T y)+c \frac{d(x, S x) d(y, T y)}{1+d(x, y)}
$$

for all $x, y \in \overline{\mathrm{B}}\left(\mathrm{x}_{0}, \mathrm{r}\right)$, then

$$
\mathrm{d}\left(\mathrm{x}_{0}, \mathrm{~S} \mathrm{x}_{0}\right) \leqslant(1-l) \mathrm{r}
$$

where $\mathrm{a}, \mathrm{b}$, and $\mathrm{c}$ are non-negative real numbers with $\mathrm{l}=\frac{1}{1-\mathrm{b}-\mathrm{c}}<1$. Suppose that there exist $\mathrm{x}_{0} \in \mathrm{X}, \mathrm{x}_{1} \in \overline{\mathrm{B}}\left(\mathrm{x}_{0}, \mathrm{r}\right)$ such that $\alpha\left(x_{0}, x_{1}\right) \geqslant 1$. Assume that if $\left\{x_{n}\right\}$ is a sequence in $\bar{B}\left(x_{0}, r\right)$ such that $\alpha\left(x_{n}, x_{n+1}\right) \geqslant 1$ and $x_{n} \rightarrow u$ as $\mathrm{n} \rightarrow+\infty$, then $\alpha\left(x_{n}, \mathrm{u}\right) \geqslant 1$ for all $n$. Then, there exists a point $x^{*}$ in $\overline{\mathrm{B}}\left(\mathrm{x}_{0}, \mathrm{r}\right)$ such that $\mathrm{x}^{*} \in S x^{*} \cap T x^{*}$.

Corollary 2.21. Let $\mathrm{T}: \mathrm{X} \longrightarrow \mathrm{CB}(\mathrm{X})$ be $\alpha^{*}$-admissible mapping on complete metric space $(\mathrm{X}, \mathrm{d}), \mathrm{x}_{0} \in \mathrm{X}$ and $0<\mathrm{r} \in \mathbb{R}$. If $\mathrm{S}$ and $\mathrm{T}$ satisfy

$$
\alpha^{*}(T x, T y) H(T x, T y) \leqslant a d(x, T x)+b d(y, T y)+c \frac{d(x, T x) d(y, T y)}{1+d(x, y)}
$$

for all $x, y \in \bar{B}\left(x_{0}, r\right)$, then

$$
\mathrm{d}\left(\mathrm{x}_{0}, \mathrm{~T} \mathrm{x}_{0}\right) \leqslant(1-l) \mathrm{r}
$$

where $\mathrm{a}, \mathrm{b}$, and $\mathrm{c}$ are non-negative real numbers with $\mathrm{l}=\frac{1}{1-\mathrm{b}-\mathrm{c}}<1$. Suppose that there exist $\mathrm{x}_{0} \in \mathrm{X}, \mathrm{x}_{1} \in \overline{\mathrm{B}}\left(\mathrm{x}_{0}, \mathrm{r}\right)$ such that $\alpha\left(x_{0}, x_{1}\right) \geqslant 1$. Assume that if $\left\{x_{n}\right\}$ is a sequence in $\bar{B}\left(x_{0}, r\right)$ such that $\alpha\left(x_{n}, x_{n+1}\right) \geqslant 1$ and $x_{n} \rightarrow u$ as $\mathrm{n} \rightarrow+\infty$, then $\alpha\left(x_{n}, u\right) \geqslant 1$ for all $n$. Then, there exists a point $x^{*}$ in $\bar{B}\left(x_{0}, r\right)$ such that $x^{*} \in T x^{*}$.

\section{Applications}

As an application, we prove the following homotopy result.

Theorem 3.1. Let $(\mathrm{X}, \mathrm{d})$ be a complete complex-valued metric space with $\mathrm{U}$ be an open subset of $\mathrm{X}$. Let $\mathrm{F}$ : $[0,1] \times \overline{\mathrm{U}} \rightarrow \mathrm{CB}(\mathrm{X})$ be multivalued mapping with g.l.b property. Suppose there exists $\stackrel{\mathrm{\zeta}}{\in} \mathrm{X}$ and $0 \prec \mathrm{r} \in \mathbb{C}$ such that

(a) $\zeta \notin[\mathrm{F}(\mathrm{t}, \zeta)]$, for each $\zeta \in \mathrm{\partial U}$ and each $\mathrm{t} \in[0,1]$;

(b) $\mathrm{F}(\mathrm{t}, \cdot): \overline{\mathrm{U}} \rightarrow \mathrm{CB}(\mathrm{X})$ be a multivalued mapping satisfying

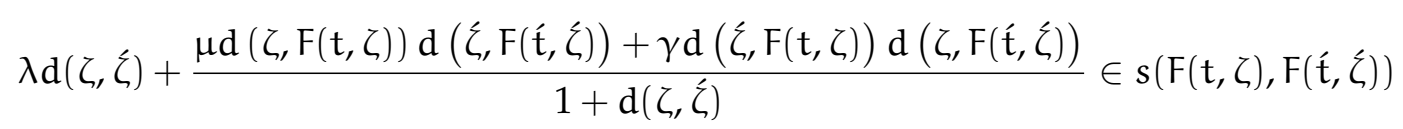

and

where $\mathrm{k}=\frac{\lambda}{1-\mu}<1$;

$$
(1-k) r \in s(\stackrel{\circ}{\zeta}, F(\stackrel{\circ}{\mathrm{t}}, \stackrel{\circ}{\zeta}))
$$

(c) there exists a continuous increasing function $\varphi:(0,1] \rightarrow \mathrm{P} \cup\{0\}$ such that;

$$
\varphi(s)-\varphi(\mathrm{t}) \in \mathrm{s}(\mathrm{F}(\mathrm{s}, \zeta), \mathrm{F}(\mathrm{t}, \zeta)) \text { and } \varphi(\mathrm{s}) \in \varphi(\mathrm{t})
$$

for all $\mathrm{s}, \mathrm{t} \in[0,1]$ and each $\zeta \in \overline{\mathrm{U}}$ where $\mathrm{P}=\{z \in \mathbb{C}: z \succ 0\}$.

Then $\mathrm{F}(0, \cdot)$ has a fixed point if and only if $\mathrm{F}(1, \cdot)$ has a fixed point.

Proof. Suppose $\mathrm{F}(0, \cdot)$ has a fixed point $z$, so $z \in \mathrm{F}(0, z)$. From $(\mathrm{a}), z \in \mathrm{U}$. Define

$$
\mathcal{Q}:=\{(\mathrm{t}, \zeta) \in[0,1] \times \mathrm{U}: \zeta \in \mathrm{F}(\zeta, \mathrm{t})\} .
$$

Clearly $Q \neq \phi$. We define the partial ordering in $Q$ as;

$$
(\mathrm{t}, \zeta) \precsim(\mathrm{s}, \zeta) \Leftrightarrow \mathrm{t} \leqslant \mathrm{s} \text { and } \mathrm{d}(\zeta, \zeta) \preceq \frac{2}{1-\mathrm{k}}(\varphi(\mathrm{s})-\varphi(\mathrm{t})) .
$$

Let $\mathcal{M}$ be a totally ordered subset of $\mathcal{Q}$ and $\stackrel{\circ}{t}=\sup \{t:(t, \zeta) \in \mathcal{M}\}$. Consider a sequence $\left\{\left(t_{n}, \zeta_{n}\right)_{n} \geqslant 0\right\}$ in $\mathcal{M}$ 
such that, $\left(t_{n}, \zeta_{n}\right) \precsim\left(t_{n+1}, \zeta_{n+1}\right)$ and $t_{n} \rightarrow \stackrel{\circ}{t}$ as $n \rightarrow \infty$. Then for $m>n$, we have

$$
\mathrm{d}\left(\zeta_{\mathrm{m}}, \zeta_{\mathrm{n}}\right) \preceq \frac{2}{1-\mathrm{k}}\left(\varphi\left(\mathrm{t}_{\mathrm{m}}\right)-\varphi\left(\mathrm{t}_{\mathrm{n}}\right)\right) \rightarrow 0, \text { as } \mathrm{n}, \mathrm{m} \rightarrow \infty,
$$

which implies that $\left\{\zeta_{n}\right\}$ is a Cauchy sequence. Since $(X, d)$ is complete complex-valued metric space, so there exists $\check{\zeta}_{i} \in X$, such that $\zeta_{n} \rightarrow \check{\zeta}_{\text {. Choose }} n_{0} \in N$, such that for all $n \geqslant n_{0}$, we have

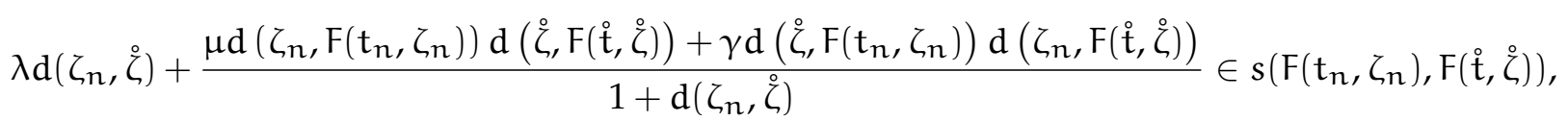

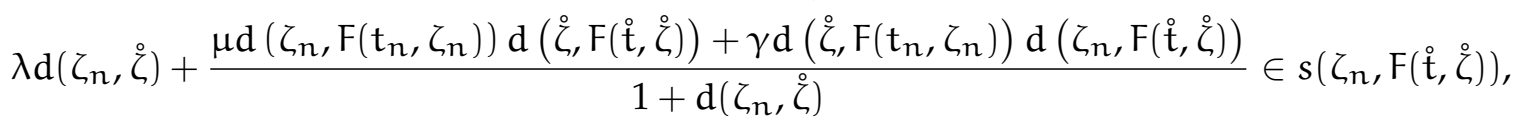

since $\zeta_{n} \in F\left(t_{n}, \zeta_{n}\right)$. So there exists some $\zeta_{k} \in F(\stackrel{\circ}{t}, \stackrel{\circ}{\zeta})$, such that

$$
\mathrm{d}\left(\zeta_{n}, \zeta_{k}\right) \preceq \lambda \mathrm{d}\left(\zeta_{n}, \stackrel{\circ}{\zeta}\right)+\frac{\mu \mathrm{d}\left(\zeta_{n}, \mathrm{~F}\left(\mathrm{t}_{\mathrm{n}}, \zeta_{\mathrm{n}}\right)\right) \mathrm{d}(\stackrel{\circ}{\zeta}, \mathrm{F}(\stackrel{\circ}{\mathrm{t}}, \stackrel{\circ}{\zeta}))+\gamma \mathrm{d}\left(\stackrel{\circ}{\zeta}, \mathrm{F}\left(\mathrm{t}_{n}, \zeta_{\mathrm{n}}\right)\right) \mathrm{d}\left(\zeta_{n}, \mathrm{~F}(\stackrel{\circ}{\mathrm{t}}, \stackrel{\circ}{\zeta})\right)}{1+\mathrm{d}\left(\zeta_{n}, \stackrel{\circ}{\zeta}\right)} .
$$

By using the greatest lower bound property (g.l.b property) of $F$, we get

$$
\mathrm{d}\left(\zeta_{n}, \zeta_{k}\right) \preceq \lambda \mathrm{d}\left(\zeta_{n}, \stackrel{\circ}{\zeta}\right)+\frac{\gamma \mathrm{d}\left(\stackrel{\circ}{\zeta}, \zeta_{n}\right) \mathrm{d}\left(\zeta_{n}, \zeta_{k}\right)}{1+\mathrm{d}\left(\zeta_{n}, \stackrel{\circ}{\zeta}\right)}
$$

which implies that

$$
\left|\mathrm{d}\left(\zeta_{n}, \zeta_{k}\right)\right| \leqslant \lambda\left|\mathrm{d}\left(\zeta_{n}, \stackrel{\circ}{\zeta}\right)\right|+\frac{\gamma\left|\mathrm{d}\left(\stackrel{\circ}{\zeta}, \zeta_{n}\right) \| \mathrm{d}\left(\zeta_{n}, \zeta_{k}\right)\right|}{\left|1+\mathrm{d}\left(\zeta_{n}, \stackrel{\circ}{\zeta}\right)\right|},
$$

since $\left|1+d\left(\zeta_{n}, \stackrel{\circ}{\zeta}\right)\right|>\left|d\left(\zeta_{n}, \stackrel{\circ}{\zeta}\right)\right|$, so we have

$$
\left|\mathrm{d}\left(\zeta_{n}, \zeta_{k}\right)\right| \leqslant \lambda\left|\mathrm{d}\left(\zeta_{n}, \stackrel{\circ}{\zeta}\right)\right|+\gamma\left|\mathrm{d}\left(\zeta_{n}, \zeta_{k}\right)\right|, \quad\left|\mathrm{d}\left(\zeta_{n}, \zeta_{k}\right)\right| \leqslant \frac{\lambda}{1-\gamma}\left|\mathrm{d}\left(\zeta_{n}, \stackrel{\circ}{\zeta}\right)\right| .
$$

Consider

$$
\left|\mathrm{d}\left(\check{\zeta}_{,}, \zeta_{k}\right)\right| \leqslant\left|\mathrm{d}\left(\dot{\zeta}_{,}, \zeta_{n}\right)\right|+\left|\mathrm{d}\left(\zeta_{\mathrm{n}}, \zeta_{\mathrm{k}}\right)\right| \leqslant\left|\mathrm{d}\left(\dot{\circ}, \zeta_{\mathrm{n}}\right)\right|+\frac{\lambda}{1-\gamma}\left|\mathrm{d}\left(\zeta_{\mathrm{n}}, \stackrel{\circ}{)}\right)\right| \rightarrow 0 \text { for all } \mathrm{n} \geqslant \mathrm{n}_{0} .
$$

Thus $\zeta_{k} \rightarrow \dot{\zeta} \in \mathrm{F}(\stackrel{\circ}{\mathrm{t}}, \stackrel{\circ}{\zeta})$ and hence $\dot{\zeta} \in \mathrm{U}$ implies $(\stackrel{\circ}{\mathrm{t}}, \stackrel{\circ}{\zeta}) \in \mathcal{Q}$. Thus $(\mathrm{t}, \zeta) \precsim(\stackrel{\circ}{\mathrm{t}}, \stackrel{\circ}{\zeta})$ for all $(\mathrm{t}, \zeta) \in \mathcal{M}$, this gives that $(\dot{t}, \stackrel{\varrho}{\zeta})$ is an upper bound of $\mathcal{M}$. Hence by Zorn's Lemma $Q$ has maximal element $(\stackrel{\leftrightarrow}{t}, \stackrel{\zeta}{\zeta})$. We claim $\dot{t}=1$, on the contrary suppose that $\stackrel{\mathrm{t}}{\mathrm{a}} \leqslant 1$, choose $0 \prec r \in \mathbb{C}$, and $\stackrel{\mathrm{t}}{\leqslant} \leqslant \mathrm{t}$, such that

$$
\overline{\mathrm{B}}(\stackrel{\circ}{\zeta}, \mathrm{r}) \subset \mathrm{U} \text {, where } \mathrm{r}=\frac{2}{1-\mathrm{k}}(\varphi(\mathrm{t})-\varphi(\stackrel{\circ}{\mathrm{t}})) .
$$

Using (c), we have

$$
\begin{aligned}
& \varphi(\mathrm{t})-\varphi(\stackrel{\circ}{\mathrm{t}}) \in \mathrm{s}(\mathrm{F}(\mathrm{t}, \zeta), \mathrm{F}(\stackrel{\circ}{\mathrm{t}}, \stackrel{\circ}{\zeta})), \\
& \varphi(t)-\varphi(\stackrel{\circ}{\mathrm{t}}) \in s(\stackrel{\circ}{\zeta}, \mathrm{F}(\mathrm{t}, \zeta)) \text { for all } \stackrel{\circ}{\zeta} \in \mathrm{F}(\stackrel{\circ}{\mathrm{t}}, \stackrel{\circ}{\zeta}) \text {. }
\end{aligned}
$$

So there exists some $\zeta \in F(t, \zeta)$, such that

$$
\varphi(\mathrm{t})-\varphi(\stackrel{\circ}{\mathrm{t}}) \in \mathrm{s}(\mathrm{d}(\stackrel{\circ}{\zeta}, \zeta))
$$

so that

$$
\mathrm{d}(\zeta, \stackrel{\circ}{\zeta}) \preceq \varphi(\mathrm{t})-\varphi(\stackrel{\circ}{\mathrm{t}}) \preceq \frac{(1-\mathrm{k}) \mathrm{r}}{2} \prec(1-\mathrm{k}) \mathrm{r},
$$


which implies that

$$
|\mathrm{d}(\zeta, \stackrel{\circ}{\zeta})| \leqslant(1-\mathrm{k})|\mathrm{r}|
$$

Also by using (b), we conclude that the mapping $F(t, \cdot): \bar{B}(\stackrel{\circ}{\zeta}, r) \rightarrow C B(X)$ satisfies all assumptions of Corollary 2.12 for all $t \in[0,1]$. Hence for all $t \in[0,1]$ there exists $\zeta \in \bar{B}(\stackrel{\circ}{\zeta}, r)$ such that $\zeta \in F(t, \zeta)$. Thus $(\zeta, t) \in Q$. Since

$$
\mathrm{d}(\zeta, \stackrel{\circ}{\zeta}) \prec \mathrm{r}=\frac{2}{1-\mathrm{k}}(\varphi(\mathrm{t})-\varphi(\grave{\mathrm{t}})),
$$

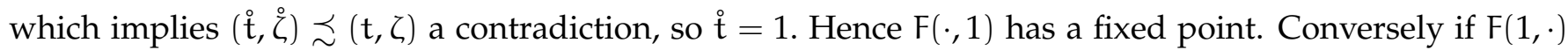
has a fixed point, then on the same way we can prove that $F(0, \cdot)$ has a fixed point.

\section{Acknowledgment}

The authors would like to acknowledge the grant UKM Grant GP-K005224 and Ministry of Education, Malaysia grant FRGS/1/2014/ST06/UKM/01/1 for financial support.

\section{References}

[1] M. Abbas, M. Arshad, A. Azam, Fixed points of asymptotically regular mappings in complex-valued metric spaces, Georgian Math. J., 20 (2013), 213-221. 1

[2] M. Abbas, B. Fisher, T. Nazir, Well-Posedness and periodic point property of mappings satisfying a rational inequality in an ordered complex valued metric space, Numer. Funct. Anal. Optim., 243 (2011), 32. 1

[3] M. Arshad, J. Ahmad, On multivalued contractions in cone metric spaces without normality, Scientific World J., 2013 (2013), 3 pages. 1

[4] M. Arshad, A. Azam, P. Vetro, Some common fixed point results in cone metric spaces, Fixed Point Theory Appl., 2009 (2009), 11 pages. 1

[5] J. H. Asl, S. Rezapour, N. Shahzad, On fixed points of $\alpha-\psi$-contractive multifunctions, Fixed Point Theory Appl., 2012 (2012), 6 pages. 1

[6] A. Azam, J. Ahmad, P. Kumam, Common fixed point theorems for multi-valued mappings in complex-valued metric spaces, J. Inequal. Appl., 2013 (2013), 12 pages. 1

[7] A. Azam, B. Fisher, M. Khan, Common fixed point theorems in complex valued metric spaces, Numer. Funct. Anal. Optim., 32 (2011), 243-253. 1, 1.2, 1.3

[8] S. Banach, Sur les opérations dans les ensembles abstraits et leur application aux équations intégrales, Fund. Math., 3 (1922), 133-181. 1

[9] S.-H. Cho, J.-S. Bae, Fixed point theorems for multivalued maps in cone metric spaces, Fixed Point Theory Appl., 2011 (2011), 7 pages. 1

[10] C. Di Bari, P. Vetro, ф-pairs and common fixed points in cone metric spaces, Rend. Circ. Mat. Palermo, 57 (2008), 279-285. 1

[11] J. Hassanzadeasl, Common fixed point theorems for $\alpha$ - $\psi$-contractive type mappings, Int. J. Anal., 2013 (2013), 7 pages. 1

[12] N. Hussain, E. Karapınar, P. Salimi, F. Akbar, $\alpha$-admissible mappings and related fixed point theorems, J. Inequal. Appl., 2013 (2013), 11 pages. 1

[13] N. Hussain, E. Karapınar, P. Salimi, P. Vetro, Fixed point results for $\mathrm{G}^{\mathrm{m}}$-Meir-Keeler contractive and G- $(\alpha, \psi)-$ MeirKeeler contractive mappings, Fixed Point Theory Appl., 2013 (2013), 14 pages.

[14] E. Karapınar, B. Samet, Generalized $\alpha-\psi$ contractive type mappings and related fixed point theorems with applications, Abstr. Appl. Anal., 2012 (2012), 17 pages. 1

[15] C. Klin-eam, C. Suanoom, Some common fixed-point theorems for generalized-contractive-type mappings on complexvalued metric spaces, Abstr. Appl. Anal., 2013 (2013), 6 pages. 1

[16] M. A. Kutbi, J. Ahmad, A. Azam, On fixed points of $\alpha-\psi$-contractive multivalued mappings in cone metric spaces, Abstr. Appl. Anal., 2013 (2013), 6 pages. 1

[17] M. A. Kutbi, A. Azam, J. Ahmad, C. Di Bari, Some common coupled fixed point results for generalized contraction in complex-valued metric spaces, J. Appl. Math., 2013 (2013), 10 pages. 1

[18] B. Mohammadi, S. Rezapour, N. Shahzad, Some results on fixed points of $\alpha-\psi$-Ciric generalized multifunctions, Fixed Point Theory Appl., 2013 (2013), 10 pages. 1

[19] S. B. Nadler, Jr., Multi-valued contraction mappings, Pacific J. Math., 30 (1969), 475-478. 1

[20] F. Rouzkard, M. Imdad, Some common fixed point theorems on complex valued metric spaces, Comput. Math. Appl., 64 (2012), 1866-1874. 1

[21] B. Samet, C. Vetro, P. Vetro, Fixed point theorems for $\alpha$ - $\psi$-contractive type mappings, Nonlinear Anal., 75 (2012), 2154-2165. 1 
[22] W. Sintunavarat, Y. J. Cho, P. Kumam, Urysohn integral equations approach by common fixed points in complex-valued metric spaces, Adv. Difference Equ., 2013 (2013), 14 pages. 1

[23] W. Sintunavarat, P. Kumam, Generalized common fixed point theorems in complex valued metric spaces and applications, J. Inequal. Appl., 2012 (2012), 12 pages. 1

[24] K. Sitthikul, S. Saejung, Some fixed point theorems in complex valued metric spaces, Fixed Point Theory Appl., 2012 (2012), 11 pages. 1 